\title{
$[3+2]$ versus [2 + 2] Addition: A Density Functional Theory Study on the Mechanistic Aspects of Transition Metal-Assisted Formation of 1,2-Dinitrosoalkanes
}

\author{
Ernest Opoku, Richard Tia, and Evans Adei \\ Theoretical and Computational Chemistry Laboratory, Department of Chemistry, Kwame Nkrumah University of \\ Science and Technology, Kumasi, Ghana
}

Correspondence should be addressed to Richard Tia; richtiagh@yahoo.com

Received 11 August 2016; Accepted 21 November 2016

Academic Editor: Maria F. Carvalho

Copyright (C) 2016 Ernest Opoku et al. This is an open access article distributed under the Creative Commons Attribution License, which permits unrestricted use, distribution, and reproduction in any medium, provided the original work is properly cited.

\begin{abstract}
The pathways for the transition metal-assisted formation of 1,2-dinitrosoalkane complexes of cobalt and its congeners, have been studied using DFT/M06 with the LACVP* basis set. The activation barriers for the one-step [3 + 2] addition pathway for the formation of 1,2-dinitrosoalkanes, proposed by Bergman and Becker, are generally low compared to the activation barriers for the $[2+2]$ addition to form an intermediate, which is the first of the two-step pathway proposed by Rappé and Upton, which are very high. The barriers of the rearrangement of the Rappé intermediates to the final products by reductive elimination involving the second metal-nitrogen $\pi$-bond are also very high. The reactions of the Co complexes have lower activation barriers than Rh and Ir complexes. The barriers of the reactions involving olefins with electron-donating groups are generally lower compared to the reactions of the parent (unsubstituted) ethylene while the activation barriers for reactions of olefins with electron-withdrawing groups are generally higher compared to the parent (unsubstituted) ethylene. The one-step [3+2] pathway remains the most favoured irrespective of the metal centre or the nature of the olefin. The mechanism of the reaction is therefore settled in favour of the $[3+2]$ addition pathway.
\end{abstract}

\section{Introduction}

Brunner and Loskot reported [1-3] that the cobalt nitrosyl dimmer $[\mathrm{CpCoNO}]_{2}$, prepared by nitrosating $\mathrm{CpCo}(\mathrm{CO})_{2}$, reacted, in the presence of additional NO, with moderately strained bicyclic olefins such as norbonene to give cis-exocomplexes (1,2-dinitrosoalkanes). This type of reactions has a number of practical advantages including the reduction of steric effects associated with reactions involving direct approach to the metal centre, more efficient coordination of electron-rich olefins, and high retention of stereochemistry at the olefin.

Becker and coworkers [4] investigated the scope and mechanism of the reaction and found it to proceed well with a wide range of alkenes, including even highly substituted olefins bearing several electron-releasing alkyl groups. They also found that the dinitrosoalkanes formed in these reactions could be isolated in some instances and could be reduced with lithium aluminium hydride $\left(\mathrm{LiAlH}_{4}\right)$, thus providing a general method for converting alkenes into vicinal, primary diamines [4]. Indeed, this procedure has been shown to work satisfactorily for terminal, $\mathrm{E}$ and $\mathrm{Z}$, di-, tri-, and at least some tetrasubstituted alkenes and leads to various aliphatic 1,2-diamines [5]. Compounds incorporating the 1,2diamino functionality have important biological properties [6]. In recent years several synthetic 1,2-diamines such as 1,2-diaminoplatinum complexes have been employed as medicinal agents, in particular in chemotherapy [5]. Vicinal diamine derivatives are also being increasingly utilized in synthesis, either as chiral auxiliaries or as metallic ligands, especially in the field of catalytic asymmetric synthesis (ibid.). Schomaker et al. [7] have reported the use of the ligandbased reactivity of a series of cobalt dinitrosyl complexes for the $\mathrm{C}-\mathrm{H}$ functionalization of olefins. Schomaker et al. [8] have also demonstrated that cobalt dinitrosyl complexes can be utilized for the $[3+2]$ annulation of olefins with 
unsaturated enones and ketimines. Reactions of a series of cobalt dinitrosyl/alkene addition products with conjugate acceptors in the presence of $\mathrm{Sc}(\mathrm{OTf})_{3} / \mathrm{LHMDS}$ formed two new carbon-carbon bonds at the $\alpha$-carbon positions on the nitrosyl groups of the substrate, leading to unusual triand tetracycles, retrocycloaddition of which in the presence of norbomadiene produced functionalized tetrasubstituted bicyclic alkenes.

The requirement for $\mathrm{NO}$ in the adduct-forming step led Becker et al. [4] to suggest that $\mathrm{CpCo}(\mathrm{NO})_{2}$ may be the initially formed intermediate; they subsequently provided kinetic and spectroscopic evidence for $\mathrm{CpCo}(\mathrm{NO})_{2}$ as a reactive intermediate [9].

Zhao et al. [10] reported that 1,2-dinitrosoalkane complexes undergo deprotonation when treated with strong bases, which makes them nucleophilic at the $\alpha$-carbon position, allowing them to take part in conjugate in addition to Michael acceptors to form new carbon-carbon bonds. These functionalized dinitroso complexes can undergo olefin exchange reactions to produce the overall $\mathrm{C}-\mathrm{H}$ functionalized product. This sequence of steps-alkene binding, functionalization, and retrocycloaddition - represents an overall vinylic $\mathrm{C}-\mathrm{H}$ functionalization reaction of simple olefins which does not require the use of directing groups. An asymmetric form of this reaction pathway has been reported by Zhao et al. [10] for the synthesis of $\mathrm{C}_{1}$ - and $\mathrm{C}_{2}$-symmetric diene ligands with high enantioinduction.

Some mechanistic questions surrounding the reaction of the cobalt dinitrosyl complex $\left(\mathrm{CpCo}(\mathrm{NO})_{2}\right)$ intermediate with alkenes to form dinitrosoalkanes have not been clearly resolved. Becker and Bergman [9] measured the absolute and relative bimolecular rate constants for the reaction of $\mathrm{CpCo}(\mathrm{NO})_{2}$ with various olefins in cyclohexane at $20^{\circ} \mathrm{C}$ and observed that 2,3-dimethyl-2-butene reacted fastest of all the isomeric hexenes studied. In contrast, it has been noted that transition metal reactions involving olefin coordination usually follow the rate sequence $\mathrm{RCH}=\mathrm{CH}_{2} \gg(\mathrm{Z})-\mathrm{RCH}=\mathrm{CHR}>$ (E)-RCH=CHR, while tri- and tetrasubstituted olefins often show little tendency to react at all [11]. Therefore, that 2,3dimethyl-2-butene (a tetrasubstituted olefin) reacted at all and that, except for 1-hexene, the trend in the reactivity of the olefin is in complete reversal to the trend noted for $\mathrm{CpCo}(\mathrm{NO})_{2}$ have been considered by Becker and Bergman [9] as strong evidence that this cyclization reaction does not take place via initial olefin coordination to the cobalt atom. These workers, therefore, suggested that the reaction takes place directly-probably in a concerted fashion-between the nitrogen atoms of the nitrosyl group and the $\pi$-bond of the olefin (Scheme 1), in analogy to the classical mechanism for osmium tetraoxide olefin oxidation [12-14].

However, using ECP Hartree-Fock and GVB calculations and Pauli Principle arguments, Upton and Rappé [15, 16] have suggested that in general (given thermodynamic accessibility) a $[2+2] 4 \pi$-electron reaction where one of the component electrons is in a d-orbital will take place with low activation energies. These workers showed that the participation of a 3d-orbital makes it possible for the Pauli Principle constraints to be satisfied in a unique way that avoids the unfavorable bonding interactions in the transition state that

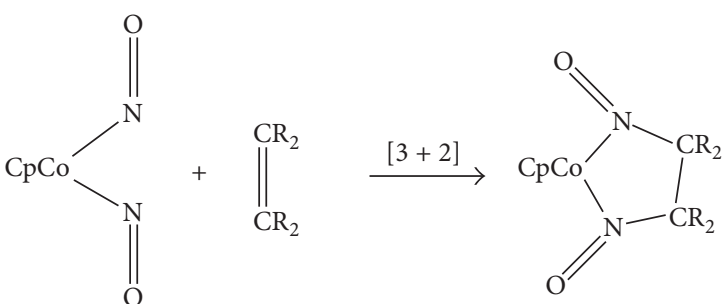

SCHEME 1: Bergman's proposed mechanism for the formation of 1,2dinitrosoalkanes.

are usually the source of the high activation energies. These workers therefore proposed a reaction sequence involving the stepwise addition of a single metal-nitrogen $\pi$-bond across the olefin $\pi$-bond, followed by a rapid reductive elimination involving the second metal-nitrogen $\pi$-bond to form the observed 1,2-dinitrosoalkane (Scheme 2), since the addition of an olefin across a metal-ligand $\pi$-bond will occur with a small activation energy (on the order of $2 \mathrm{kcal} / \mathrm{mol}$ ) and reductive elimination reactions have been shown to take place with small activation energies [17].

To date, the question as to whether the formation of 1,2-dinitrosoalkanes occurs in a concerted [3 + 2] fashion as proposed by Bergman and coworkers or by a stepwise route as proposed by Rappé and workers remains unresolved, despite the importance of this reaction. This work therefore aims at exploring the potential energy surface of the reactions of $\mathrm{CpM}(\mathrm{NO})_{2}(\mathrm{M}=\mathrm{Co}, \mathrm{Rh}$, Ir $)$ with some olefins at the DFT M06/6-31G* level of theory to investigate whether the reaction follows concerted $[3+2]$ addition pathway or stepwise pathway involving $[2+2]$ addition followed by rearrangement and to investigate the effect of changing the metal or the olefins. The geometries and relative energies of the relevant structures (reactants, transition states, intermediates, and products) along the two proposed reaction pathways (Schemes 1 and 2) are computed to provide molecular level insight into the plausible mechanistic channel(s) of the formation of 1,2-dinitrosoalkanes.

\section{Computational Details and Methodology}

All the calculations were performed with the Spartan [18] computational chemistry package developed by Wavefunction, Inc., versions 2008V1.2.0 and 2010V1.2.0, using the M06 hybrid functional [19], a hybrid meta-gradient-corrected functional (meta-GGA) with $27 \%$ of Hartree-Fock exchange. It has been benchmarked and recommended for application in transition metal chemistry [20].

The atoms hydrogen-argon were described with the 6$31 \mathrm{G}^{*}$ basis set while the metals $\mathrm{Co}, \mathrm{Rh}$, and Ir were described with the quasi-relativistic pseudopotential lanl $2 \mathrm{dz}$ basis set [21-24]. The M06/lanl2dz is one of the most popular DFT levels to the study of transition metal chemistry. In a review of DFT methods for computational studies of transition metal homogeneous organometallic catalysis involving $\mathrm{Ni}, \mathrm{Pd}, \mathrm{Ir}$, and $\mathrm{Rh}$ [25] it was reported that geometry optimization and energy calculations are dominated by the M06 functional and the lanl $2 \mathrm{~d} z$ as effective core potential for the transition metal. 


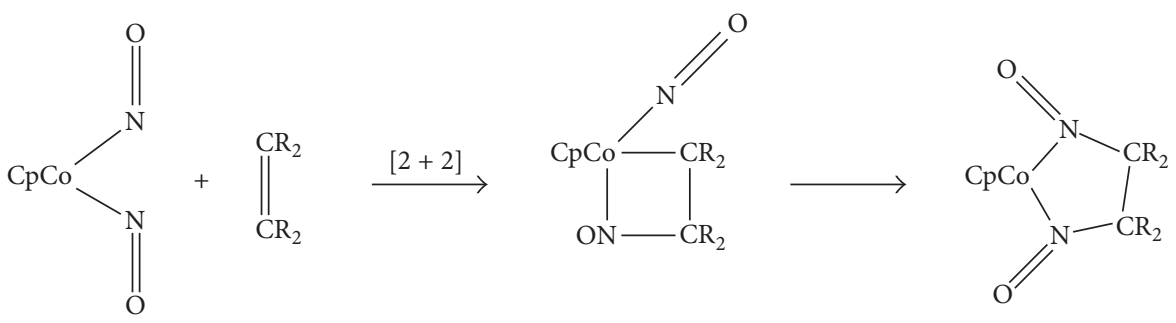

SCHEME 2: Rappé's proposed mechanism for the formation of 1,2-dinitrosoalkane.

Molecules were constructed with Spartan's and minimized interactively using MMFF force field. All structural optimizations were done without symmetry restrictions. Full frequency calculations were performed to verify that the correct stationary points were located. Minima, representing reactants, intermediates, and products were shown to have a Hessian matrix with all positive eigenvalues, characterized by all real vibrational frequencies.

Input structures for transition state optimizations were obtained by first constraining specific internal coordinates along the reaction coordinates and fully optimizing the remaining internal coordinates. The approximate transition state structures obtained this way were then submitted for transition state calculation. All transition state structures were subjected to full frequency calculations to ensure that they have a Hessian matrix with a single negative eigenvalue, characterized by an imaginary vibrational frequency along the reaction coordinate. An intrinsic reaction coordinate (IRC) calculation was performed to ensure that transition state structures located smoothly connect the reactants and products along the reaction coordinate [26].

\section{Results and Discussion}

3.1. The Reaction of CpM(NO) ${ }_{2}(M=C o, R h, I r)$ with Ethylene. Figures 1, 2, and 3 show the optimized geometries of the stationary points relevant to the two proposed mechanistic proposals as well as the Gibbs free energy profile of the reaction of $\mathrm{CpM}(\mathrm{NO})_{2}(\mathrm{M}=\mathrm{Co}, \mathrm{Rh}, \mathrm{Ir})$ with ethylene.

The activation barriers involved in the direct one-step [ 3 +2 ] addition pathway in all the three metals complexes are far lower than the activation barriers involved in the stepwise $[2+2]$ addition pathway. In the stepwise $[2+2]$ addition pathway, the first transition state involving a single metalnitrogen $\pi$-bond has a far higher activation barrier than the concerted one-step [3+2] addition pathway. Also, the second transition state along the stepwise $[2+2]$ addition pathway in the reductive elimination step involving the second metalnitrogen $\pi$-bond leading to the formation of the observed 1,2dinitrosoalkanes has higher activation barriers as compared to the direct $[3+2]$ addition pathway in all the substrates studied, indicating that the $[3+2]$ pathway is clearly favoured in the reaction of ethylene.

It has been observed that the reaction of the Co complex has marginally lower activation energy along the plausible one-step $[3+2]$ addition pathway than the Ir and $\mathrm{Rh}$ complexes, respectively. In the reaction of the ethylene and
$\mathrm{CpM}(\mathrm{NO})_{2}(\mathrm{M}=\mathrm{Co}, \mathrm{Rh}, \mathrm{Ir})$, the Co complex has an activation barrier of $11.2 \mathrm{kcal} \mathrm{mol}^{-1}$ along the direct [3+2] addition pathway as shown in Figure 1, while the Rh and Ir complexes have activation barriers of $14.2 \mathrm{kcal} \mathrm{mol}^{-1}$ and $13.0 \mathrm{kcal} \mathrm{mol}^{-1}$ as shown in Figures 2 and 3, respectively. The formation of the cobalt dinitroso complexes is more exergonic than for the $\mathrm{Rh}$ and Ir complexes, the least exergonic being the formation of the Rh dinitroso complex.

The results show that, for both kinetically and thermodynamically controlled reactions, the formation of the Co dinitroso complex is more favourable than the Ir and $\mathrm{Rh}$ metal complexes. However, in view of the need for the formation of a much less stable product for easier in situ conversion to primary vicinal diamines, the $\mathrm{Rh}$ metal complex is preferred.

In the reaction of the $\mathrm{CpCo}(\mathrm{NO})_{2}$ with ethylene, the concerted [ $3+2]$ addition pathway has an activation energy of $11.2 \mathrm{kcal} \mathrm{mol}^{-1}$ (Figure 1) to the formation of the final product. However, the first step transition state involved in the two-step [2 + 2] pathway has an activation barrier of $39.9 \mathrm{kcal} \mathrm{mol}^{-1}$, a barrier which is $28.7 \mathrm{kcal} \mathrm{mol}^{-1}$ higher than the energy barrier involved in the direct [3+2] addition pathway. Although the stepwise $[2+2]$ addition leads to the formation of less stable intermediate with endergonicity of $8.6 \mathrm{kcal} \mathrm{mol}^{-1}$, rearrangement of the intermediate to form the alkylnitroso complex requires an activation barrier of $20.3 \mathrm{kcal} \mathrm{mol}^{-1}$ which is also $9.1 \mathrm{kcal} \mathrm{mol}^{-1}$ higher than the activation energy involved in the one-step $[3+2]$ addition pathway (Figure 1). This points to the fact that the $[3+2]$ addition pathway is preferred over the $[2+2]$ pathway.

Similarly, in the reaction of the $\mathrm{CpRh}(\mathrm{NO})_{2}$ with ethylene, the one-step $[3+2]$ addition pathway has an activation barrier of $14.6 \mathrm{kcal} \mathrm{mol}^{-1}$ (Figure 2) leading to the formation of the observed 1,2-dinitrosoalkanes. However, the first step transition state involved in the two-step $[2+2]$ pathway has an activation barrier of $42.6 \mathrm{kcal} \mathrm{mol}^{-1}$, a barrier which is $28.4 \mathrm{kcal} \mathrm{mol}^{-1}$ higher than the energy barrier involved in the direct $[3+2]$ addition pathway. Although the stepwise $[2+$ 2] addition leads to the formation of less stable intermediate with endergonicity of $14.3 \mathrm{kcal} \mathrm{mol}^{-1}$, rearrangement of the intermediate to form the final product requires an activation barrier of $20.0 \mathrm{kcal} \mathrm{mol}^{-1}$ which is also $5.8 \mathrm{kcal} \mathrm{mol}^{-1}$ higher than the activation energy involved in the one-step $[3+2]$ addition pathway as shown in Figure 2. The energetics along the two pathways are consistent with the earlier observation made in the Co complex, an indication that the stepwise $[2+$ 2] addition pathway is not plausible. 


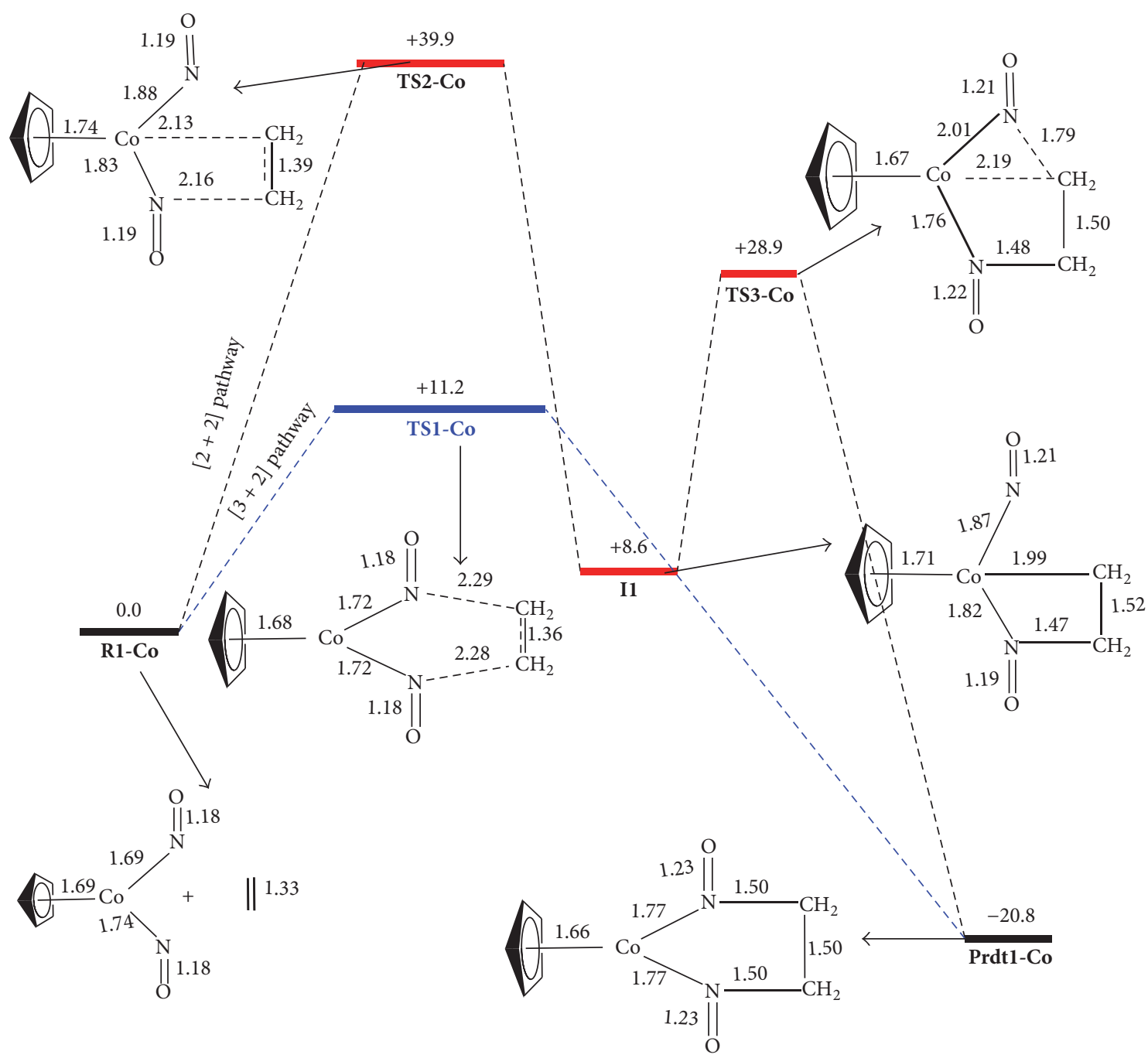

FIGURE 1: Free energy profile for the [3+2] and [2+2] addition reaction between $\mathrm{CpCo}(\mathrm{NO})_{2}$ and ethylene. Relative energies in kcal mol ${ }^{-1}$. All bond distances are measured in $\AA$.

Extending the studies to the reaction of the $\mathrm{CpIr}(\mathrm{NO})_{2}$ with ethylene, the concerted $[3+2]$ addition pathway has an activation barrier of $13.0 \mathrm{kcal} \mathrm{mol}^{-1}$ (Figure 3) leading to the formation of the observed alkylnitroso complex of Ir. However, the first step transition state involved in the two-step $[2+2]$ pathway has an activation barrier of $39.4 \mathrm{kcal} \mathrm{mol}^{-1}$, a barrier which is $26.4 \mathrm{kcal} \mathrm{mol}^{-1}$ higher than the energy barrier involved in the direct [3+2] addition pathway. Even though the stepwise $[2+2]$ addition leads to the formation of less stable intermediate with endergonicity of $5.3 \mathrm{kcal} \mathrm{mol}^{-1}$, rearrangement of the intermediate to form the final product requires an activation barrier of $32.5 \mathrm{kcal} \mathrm{mol}^{-1}$ which is also $19.5 \mathrm{kcal} \mathrm{mol}^{-1}$ higher than the activation barrier involved in the one-step [3+2] addition pathway as shown in Figure 3 . The observed energetic trends in the Ir complex are analogous to and consistent with the ones in the Co and Rh complexes, a further evidence that the stepwise [2+2] addition pathway is not feasible.
3.2. Reactions of $\mathrm{CpM}(\mathrm{NO})_{2}(\mathrm{M}=\mathrm{Co}, \mathrm{Rh}, \mathrm{Ir})$ with Substituted Olefins. To explore the effects of substituents on the energetics of the reactions, a series of reactions involving electron-withdrawing and electron-donating groups and ring substituents on the olefin were studied and the energetics are reported in Tables 1 and 2.

The optimized geometries and relative energies of the stationary points involved in the reactions of $\mathrm{CpM}(\mathrm{NO})_{2}$ $(\mathrm{M}=\mathrm{Co}, \mathrm{Rh})$ with 2-norbonene, a strained bicyclic olefin, are shown in Figures 4 and 5. From Figure 4, it is seen that the concerted $[3+2]$ addition pathway in the reaction of $\mathrm{CpCo}(\mathrm{NO})_{2}$ with 2-norbonene has an activation barrier of $9.0 \mathrm{kcal} \mathrm{mol}^{-1}$ which is the lowest activation barrier obtained in all the olefins studied in this work and the final product has a reaction energy of $-29.4 \mathrm{kcal} \mathrm{mol}^{-1}$. It is also seen that the final product formed via the concerted $[3+2]$ pathway in the reaction of the $\mathrm{CpCo}(\mathrm{NO})_{2}$ with 2-norbonene is the most stable product observed in all the olefins covered in this 


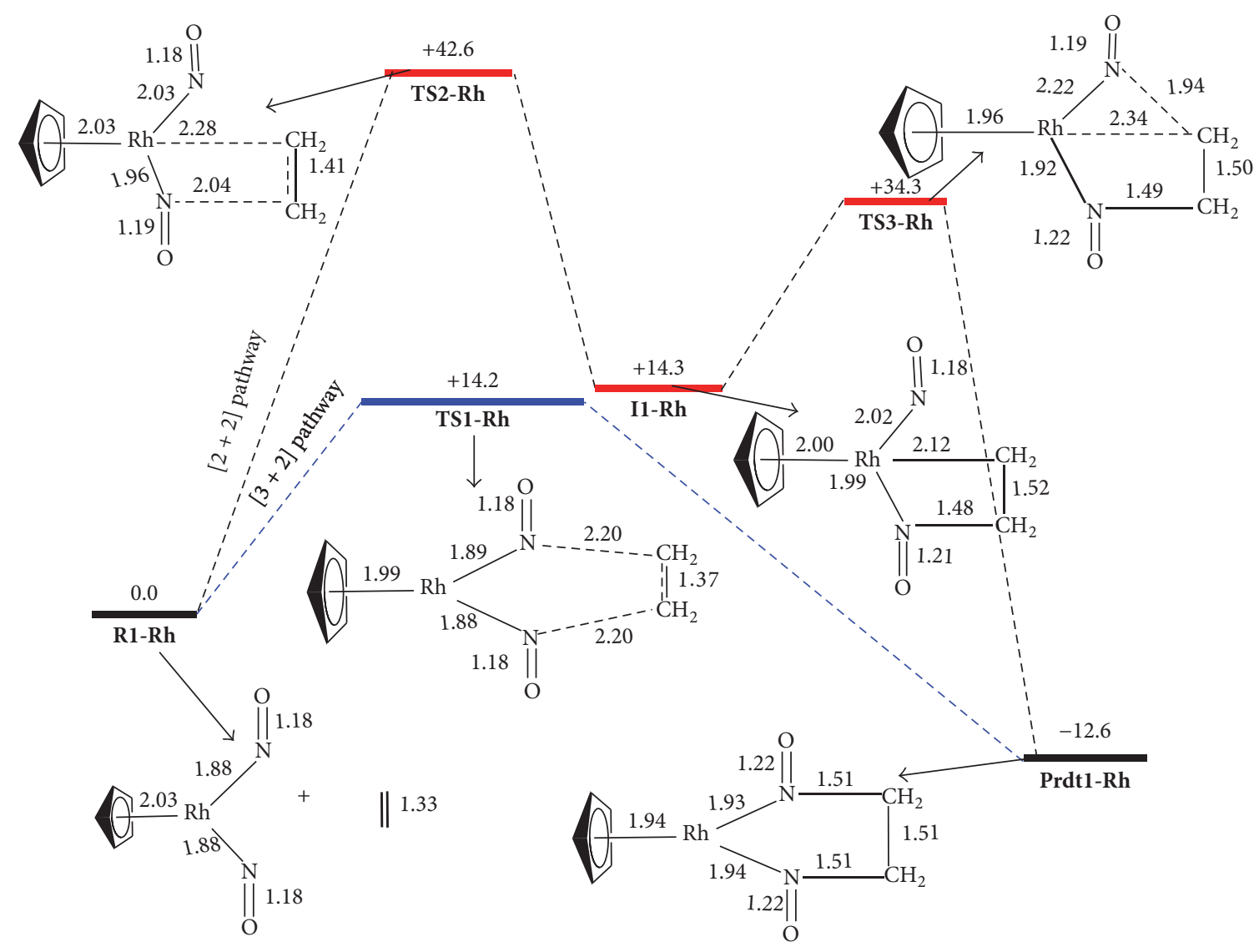

FiguRE 2: Free energy profile for the [3+2] and [2+2] addition reaction between $\mathrm{CpRh}(\mathrm{NO})_{2}$ and ethylene. Relative energies in kcal mol ${ }^{-1}$. All bond distances are measured in $\AA$.

work which is an indication that it can easily be isolated. The first step transition state TS5-Co involved in the stepwise [2+ 2] pathway has an activation barrier of $33.8 \mathrm{kcal} \mathrm{mol}^{-1}$ which is $24.8 \mathrm{kcal} \mathrm{mol}^{-1}$ higher than the energy barrier involved in the direct $[3+2]$ addition pathway. Though the stepwise $[2+$ 2] addition leads to the formation of less stable intermediate I2-Co of $8.2 \mathrm{kcal} \mathrm{mol}^{-1}$ endergonicity, rearrangement of the intermediate to form the final product involves an activation barrier of $36.6 \mathrm{kcal} \mathrm{mol}^{-1}$ which is also $27.9 \mathrm{kcal} \mathrm{mol}^{-1}$ higher than the activation energy involved in the one-step [3 + 2] addition pathway as depicted in Figure 4. Also, the second transition state TS6-Co involved in the stepwise $[2+2]$ addition is higher than the first transition state TS5-Co along the same pathway which is unusual among all the olefins covered in this work.

The direct $[3+2]$ addition of 2-norbonene across the $\mathrm{Rh}-\mathrm{N}$ bonds of $\mathrm{CpRh}(\mathrm{NO})_{2}$ has an activation barrier of $11.3 \mathrm{kcal} \mathrm{mol}^{-1}$ (Figure 5) which is the lowest activation barrier obtained in the reaction of the $\mathrm{CpRh}(\mathrm{NO})_{2}$ and all the olefins studied in this work. The observed final product has a reaction energy of $20.9 \mathrm{kcal} \mathrm{mol}^{-1}$ exergonicity which is the most stable product observed among the Rh complex with all the olefins covered in this work. The first step transition state TS5-Rh involved in the stepwise $[2+2]$ pathway has an activation barrier of $36.3 \mathrm{kcal} \mathrm{mol}^{-1}$ (Figure 5) which is
$22.5 \mathrm{kcal} \mathrm{mol}^{-1}$ higher than the energy barrier involved in the direct [3+2] addition pathway. In spite of the stepwise [2+2] addition leading to the formation of a less stable intermediate I2-Rh of $13.0 \mathrm{kcal} \mathrm{mol}^{-1}$ endergonicity, rearrangement of the intermediate to form the final product involves an activation barrier of $36.9 \mathrm{kcal} \mathrm{mol}^{-1}$ (TS6-Rh) which is $25.6 \mathrm{Kcal} \mathrm{mol}^{-1}$ above the activation energy involved in the one-step $[3+$ 2] addition pathway as shown in Figure 5. Here again, the second transition state TS6-Rh involved in the stepwise [2+ 2] addition pathway is slightly higher than the first transition state TS5-Rh as occurred in its cobalt counterpart.

The addition of 2-norbonene across the Ir- $\mathrm{N}$ bonds of $\mathrm{CpIr}(\mathrm{NO})_{2}$ formed a final product with a reaction energy of $28.2 \mathrm{kcal} \mathrm{mol}^{-1}$ exergonicity which is the most stable product observed among all the reactions of the Ir complex with all the olefins studied. The first step transition state involved in the stepwise $[2+2]$ pathway has an activation barrier of $31.5 \mathrm{kcal} \mathrm{mol}^{-1}$. Although the stepwise [2+2] addition leads to the formation of a less stable intermediate of $3.6 \mathrm{kcal} \mathrm{mol}^{-1}$ endergonicity, rearrangement of the intermediate to form the final product involves an activation barrier of $49.3 \mathrm{kcal} \mathrm{mol}^{-1}$. The trend in the energetics for the stepwise $[2+2]$ addition for the reaction of the $\mathrm{CpRh}(\mathrm{NO})_{2}$ with 2-norbonene is consistent with the results obtained in the reaction of the $\mathrm{Co}$ and $\mathrm{Rh}$ metal complexes with 2-norbonene. Attempts to 


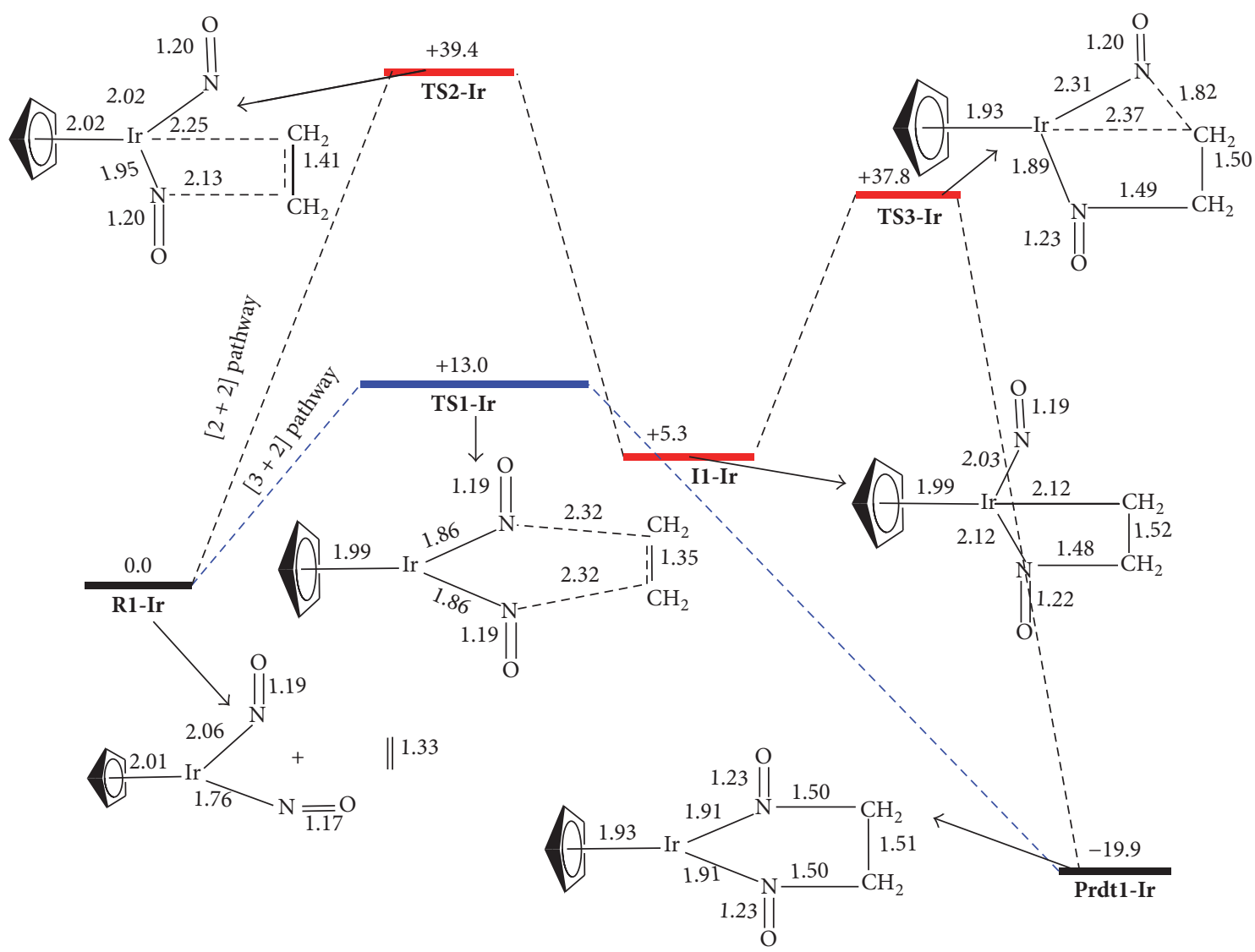

Figure 3: Free energy profile for the [3+2] and [2+2] addition reaction between CpIr $(\mathrm{NO})_{2}$ and ethylene. Relative energies in kcal mol ${ }^{-1}$. All bond distances are measured in $\AA$.

locate the transition state for the direct $[3+2]$ addition of 2 -norbonene across the $\mathrm{Ir}-\mathrm{N}$ bonds of $\mathrm{CpIr}(\mathrm{NO})_{2}$ have been unsuccessful; however from the arguments and the trends so far it is conceivable that it can be found.

The optimized geometries and Gibbs free energy profiles for the reactions of the rest of the substituted olefins studied are shown in the Supplementary Material attached as Figures S1-S33 (see Supplementary Material available online at http://dx.doi.org/10.1155/2016/4538696). As it can be seen from Table 1, the activation barriers of reactions of olefins with electron-donating substituents are lower compared to the parent (unsubstituted) ethylene except for propene However, the activation barriers for olefins with electronwithdrawing substituents are generally found to be higher compared to the parent (unsubstituted) ethylene except for acrylonitrile in the Co complex. For the ring systems studied, 2-norbonene has the lowest activation barrier for the direct one-step $[3+2]$ addition pathway. Also, among all the olefin substrates considered in this work, 2-norbonene had the lowest activation energy and the highest reaction energy as well (Tables 1 and 2) along the concerted [3+ 2] addition pathway. The high reactivity of 2-norbonene compared to the other ring systems considered in this work could be attributed to the degree of ring strain. This is in agreement to the suggestion by Brunner [1] that the reaction proceeds well with highly strained bicyclic structures and leads to the formation of a stable and isolable 1,2dinitrosoalkanes.

It has been observed that the Co complex has marginally lower activation barriers along the plausible direct one-step $[3+2]$ addition pathway than the $\mathrm{Ir}$ and $\mathrm{Rh}$ complexes irrespective of the nature of the olefin. Consistently, lower reaction energy was observed in the $\mathrm{Rh}$ complex as compared to the Ir and Co complexes irrespective of the nature of the olefin. Also, among all the olefins considered in this work, acrylonitrile leads to the formation of the least stable alkylnitroso complex in all the three metal complexes (Table 2). The direct concerted [ $3+2]$ addition pathway remains the most favoured irrespective of the nature of the olefin and the nature of the metal complex used.

In the reaction of the cobalt dinitrosyl complex and olefins with electron-donating substituents, OH (Figure S10) and $\mathrm{NH}_{2}$ (Figure S13) substituted ethylene recorded the lowest activation barriers; however the stability of the final product for the $\mathrm{NH}_{2}$ substituted ethylene along the plausible concerted $[3+2]$ addition pathway is far lower than the $\mathrm{OH}$ substituted ethylene.

For ethylene with electron-withdrawing substituents, the CN substituted ethylene (Figure S16) has the lowest activation barrier. Though all the products formed from the reaction 
TABLE 1: Activation barriers for the formation of the dinitrosoalkanes through [3+2] and [2+2] addition involving various olefins. All energies are measured in $\mathrm{kcal} \mathrm{mol}^{-1}$.

\begin{tabular}{|c|c|c|c|c|c|c|c|c|c|}
\hline \multirow{2}{*}{ Olefin/substituent } & \multicolumn{3}{|c|}{ Cobalt } & \multicolumn{3}{|c|}{ Rhodium } & \multicolumn{3}{|c|}{ Iridium } \\
\hline & {$[3+2]$} & {$[2+2]^{\mathrm{a}}$} & {$[2+2]^{\mathrm{b}}$} & {$[3+2]$} & {$[2+2]^{\mathrm{a}}$} & {$[2+2]^{\mathrm{b}}$} & {$[3+2]$} & {$[2+2]^{\mathrm{a}}$} & {$[2+2]^{\mathrm{b}}$} \\
\hline Ethylene & +11.2 & +39.8 & +28.9 & +14.2 & +42.6 & +34.3 & +13.0 & +39.4 & +37.8 \\
\hline Propene & +11.8 & +44.5 & +29.6 & +14.7 & +43.2 & +36.0 & +13.4 & +43.7 & +39.3 \\
\hline Transbutene & +10.9 & +41.1 & +29.1 & +14.3 & +43.5 & +36.2 & +13.0 & +39.6 & +39.1 \\
\hline 2,3-Dimethyl-2-butene & +10.4 & +40.6 & +34.8 & +12.6 & +43.0 & +40.8 & +12.4 & +38.2 & 44.9 \\
\hline Ethenol & +10.1 & +44.6 & +34.3 & +13.3 & +47.6 & +38.8 & +11.5 & +43.3 & +44.3 \\
\hline Aminoethene & +10.1 & +49.0 & +30.5 & +12.9 & +49.9 & +35.7 & +11.5 & +47.8 & +39.8 \\
\hline Vinyl fluoride & +13.0 & +47.5 & +35.7 & +16.5 & +53.2 & +40.4 & +15.0 & +46.2 & +45.7 \\
\hline Acrylonitrile & +11.0 & +38.7 & +31.8 & +15.2 & +42.5 & +36.5 & +13.3 & +42.8 & +41.8 \\
\hline 3,3,3-Trifluoro-1-propene & +12.1 & +42.1 & +31.7 & +16.0 & +43.7 & +36.6 & +14.7 & +41.9 & +40.8 \\
\hline Cyclobutene & +10.9 & +41.4 & +30.1 & +13.4 & +43.1 & +35.7 & +12.9 & +39.7 & +38.8 \\
\hline Cyclopentene & +13.7 & +38.6 & +33.7 & +16.7 & +43.3 & +40.3 & +15.6 & +38.9 & +43.9 \\
\hline 2-Cyclohexenone & +10.6 & +34.8 & +33.1 & +17.0 & +40.8 & +42.6 & +15.7 & +36.6 & +46.4 \\
\hline 2-Norbonene & +9.0 & +33.8 & +44.8 & +11.3 & +36.3 & +49.9 & - & +31.5 & +52.9 \\
\hline
\end{tabular}

${ }^{a}$ Barriers of the first step of the two-step pathway. ${ }^{b}$ Barriers of the second step of the two-step pathway.

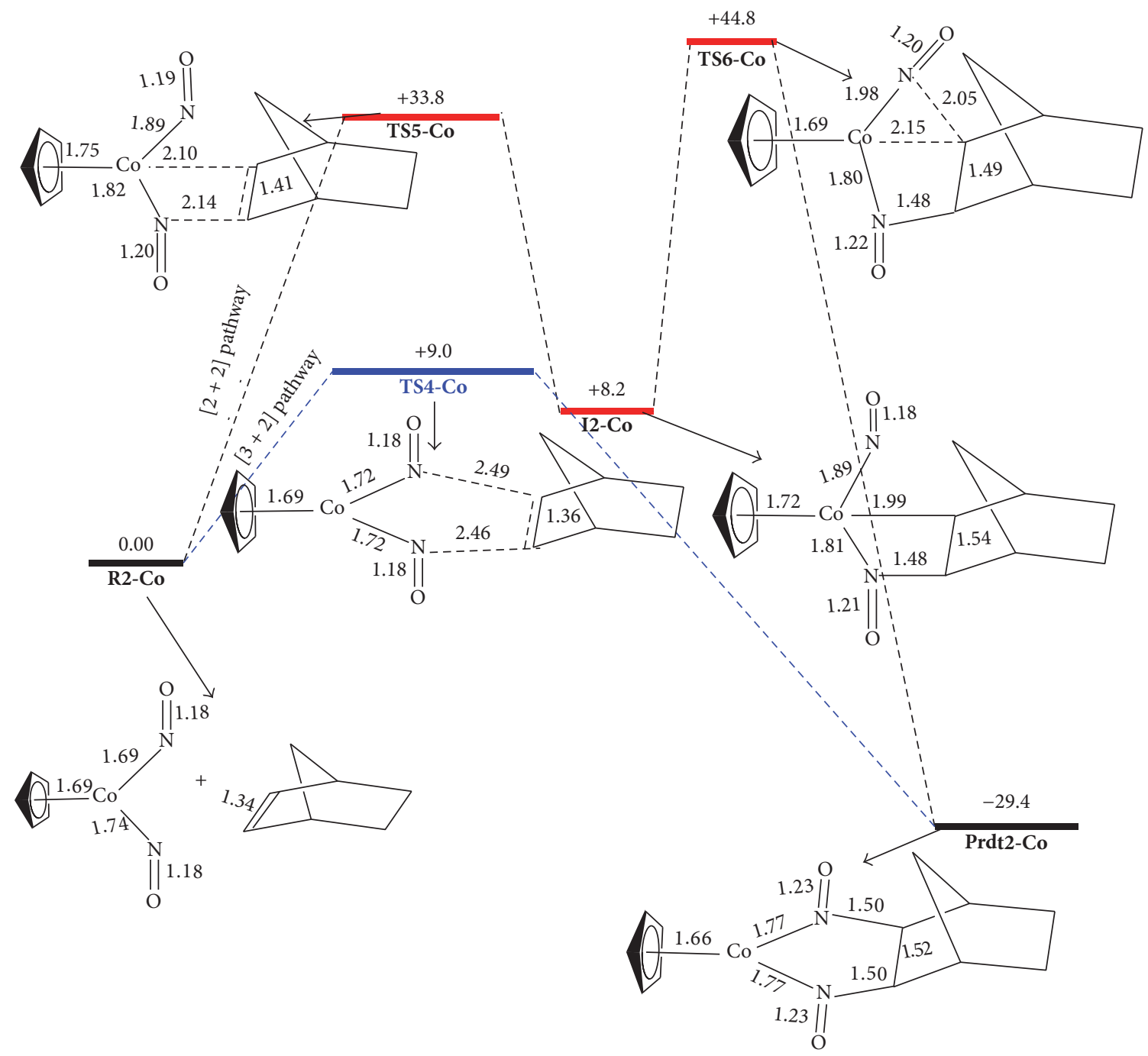

Figure 4: Free energy profile of the $[3+2]$ and $[2+2]$ addition reaction between $\mathrm{CpCo}(\mathrm{NO})_{2}$ and 2-norbonene. Relative energies in $\mathrm{kcal} \mathrm{mol}^{-1}$. All bond distances are measured in $\AA$. 


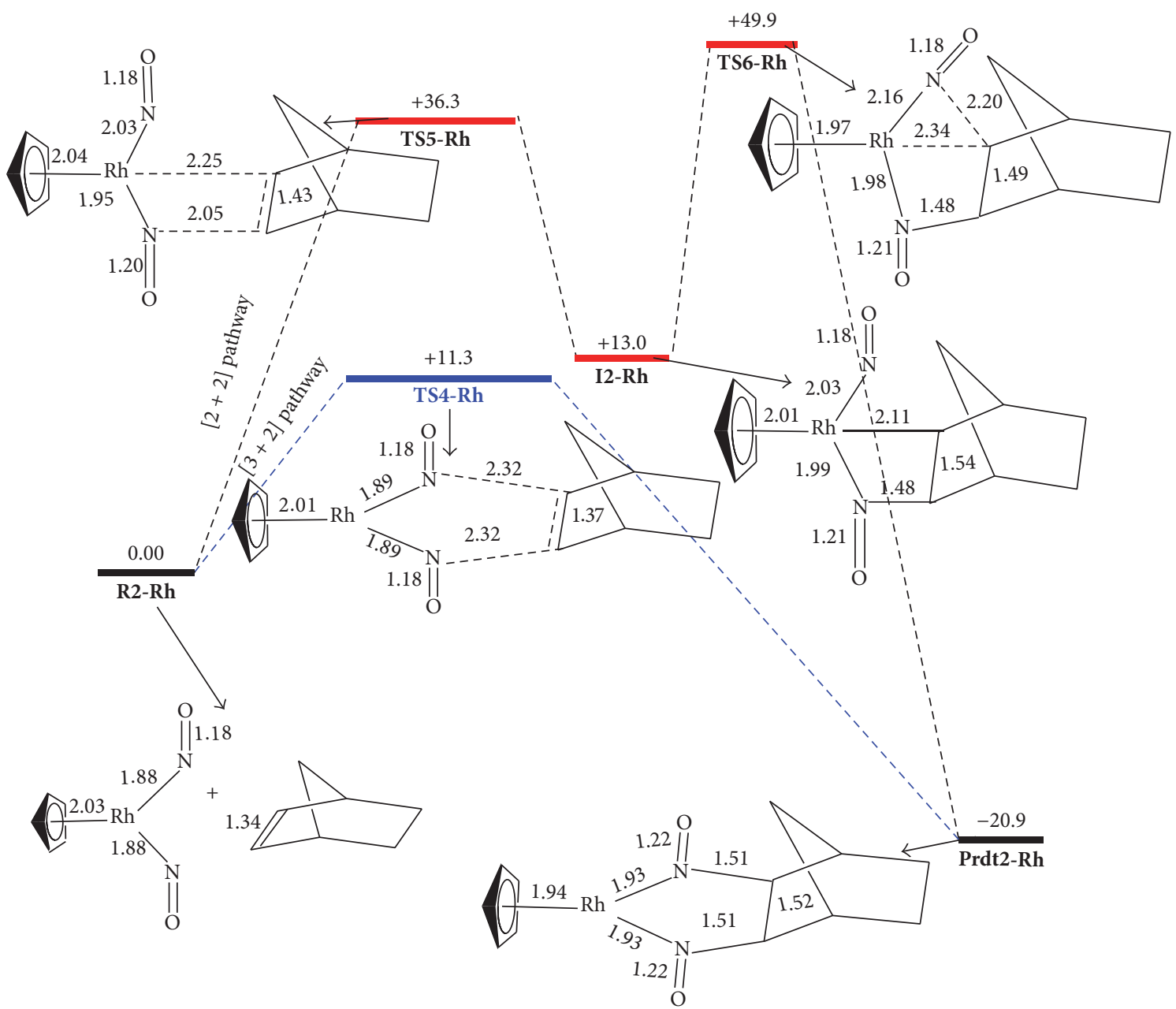

FIGURE 5: Free energy profile of the [3+2] and [2+2] addition reaction between $\mathrm{CpRh}(\mathrm{NO})_{2}$ and 2-norbonene. Relative energies in kcal mol ${ }^{-1}$. All bond distances are measured in $\AA$.

TABLE 2: Reaction energies of the [3+2] final products involving various olefins. All energies are measured in $\mathrm{kcal} \mathrm{mol}^{-1}$.

\begin{tabular}{lccc}
\hline Olefin/substituent & Cobalt & Rhodium & Iridium \\
\hline Ethylene & -20.8 & -12.6 & -19.9 \\
Propene & -20.2 & -12.0 & -19.1 \\
Transbutene & -20.3 & -11.5 & -19.3 \\
2,3-Dimethyl-2-butene & -22.1 & -13.3 & -20.2 \\
Ethenol & -22.4 & -13.3 & -20.9 \\
Aminoethene & -16.4 & -7.7 & -14.7 \\
Vinyl fluoride & -17.6 & -8.9 & -16.5 \\
Acrylonitrile & -12.4 & -3.3 & -10.4 \\
3,3,3-Trifluoro-1-propene & -17.5 & -8.5 & -15.8 \\
Cyclobutene & -26.4 & -18.6 & -25.7 \\
Cyclopentene & -21.1 & -12.8 & -20.0 \\
2-Cyclohexenone & -10.5 & -3.3 & -9.9 \\
2-Norbonene & -29.4 & -20.9 & -28.2 \\
\hline
\end{tabular}

of the cobalt dinitrosyl complex and olefins with electronwithdrawing substituents such as F (Figure S7), CN (Figure
S16), and $\mathrm{CF}_{3}$ (Figure S19) substituted ethylene are generally less stable compared to the parent ethylene, the CN substituted ethylene gives the least stable product.

Also, for monocyclic olefins cyclobutene (Figure S25) has lower activation barrier than the cyclopentene (Figure S28); however, the cyclopentene leads to a less stable product than the cyclobutene and 2-cyclohexenone has a lower activation barrier as compared to the parent ethylene. Also the 2cyclohexenone formed the least stable product among all the substrates considered in this work.

Analogous trends in energetics were observed in the reactions of the rhodium and iridium dinitrosyl complexes with the various olefins. Detailed results and reaction profiles of the reaction of the metal dinitrosyl complexes and the various olefins are reported in the Supplementary Material.

\section{Conclusions}

From the results discussed, the following conclusions are drawn:

(1) The direct one-step [3+2] addition pathway proposed by Bergman and Becker is the most plausible pathway 
for the formation of 1,2-dinitrosoalkanes since the activation barriers for the one-step $[3+2]$ addition pathway are generally very low compared to the barriers for the stepwise $[2+2]$ addition pathway irrespective of the nature of the olefin.

(2) The order in the activation barriers with respect to changing metal is $\mathrm{Rh}>\mathrm{Ir}>\mathrm{Co}$ for each of the olefins studied while the trend for product stability is $\mathrm{Co}>\mathrm{Ir}$ $>\mathrm{Rh}$.

(3) Olefins with electron-donating substituents generally have lower activation barriers and higher product stability compared to the parent (unsubstituted) ethylene.

(4) Olefins with electron-withdrawing substituents generally have higher activation barriers and lower product stability compared to the parent (unsubstituted) ethylene except for acrylonitrile in the Co complex.

(5) For one-member cycloalkenes, activation barriers increase with increasing ring size while product stability decreases with decreasing ring size.

(6) Reactions with cycloalkenes containing the enone functionality have lower activation energies and very low reaction energies.

(7) Moderately strained bicyclic olefins recorded the lowest activation barriers and the highest reaction energies.

\section{Competing Interests}

The received funding in the "Acknowledgments" section did not lead to any conflict of interests regarding the publication of this manuscript. The authors declare that there is no conflict of interests whatsoever regarding this manuscript.

\section{Acknowledgments}

The authors are very grateful to the National Council for Tertiary Education, Republic of Ghana, for a research grant under the Teaching and Learning Innovation Fund (TALIF/KNUST/3/0008/2005).

\section{References}

[1] H. Brunner, "Über nitrosyl-metall-komplexe III. Cyclopentadienylnitrosylkobalt," Journal of Organometallic Chemistry, vol. 12, no. 3, pp. 517-522, 1968.

[2] H. Brunner and S. Loskot, "Incorporation of olefin and nitric oxide into organocobalt compounds," Angewandte Chemie International Edition, vol. 10, no. 7, pp. 515-516, 1971.

[3] H. Brunner and S. Loskot, "Über nitrosyl-metall-komplexe: XV. Die reaktion von organokobalt-verbindungen mit no und olefinen-eine neue dreikomponentensynthese," Journal of Organometallic Chemistry, vol. 61, pp. 401-414, 1973.

[4] P. N. Becker, M. A. White, and R. G. Bergman, "A new method for 1,2-diamination of alkenes using cyclopentadienylnitrosylcobalt dimer/ $\mathrm{NO} / \mathrm{LiAlH}_{4}$," Journal of the American Chemical Society, vol. 102, no. 17, pp. 5676-5677, 1980.
[5] D. Lucet, T. Le Gall, and C. Mioskowski, "The chemistry of vicinal diamines," Angewandte Chemie-International Edition, vol. 37, no. 19, pp. 2580-2627, 1998.

[6] G. Michalson, Kant's Religion within the Boundaries of Mere Reason, Cambridge University Press, Cambridge, UK, 2014.

[7] J. M. Schomaker, W. C. Boyd, I. C. Stewart, F. D. Toste, and R. G. Bergman, "Cobalt dinitrosoalkane complexes in the C-H functionalization of olefins," Journal of the American Chemical Society, vol. 130, no. 12, pp. 3777-3779, 2008.

[8] J. M. Schomaker, F. D. Toste, and R. G. Bergman, "Cobaltmediated $[3+2]$-annulation reaction of alkenes with $\alpha, \beta$ unsaturated ketones and imines," Organic Letters, vol. 11, no. 16, pp. 3698-3700, 2009.

[9] P. N. Becker and R. G. Bergman, "Reversible exchange of $\left(\eta^{5}\right.$-cyclopentadienyl)(dinitrosoalkane)cobalt complexes with alkenes. Kinetic and spectroscopic evidence for cyclopentadienyldinitrosylcobalt as a reactive intermediate," Journal of the American Chemical Society, vol. 105, no. 10, pp. 2985-2995, 1983.

[10] C. Zhao, M. R. Crimmin, F. D. Toste, and R. G. Bergman, "Ligand-based carbon-nitrogen bond forming reactions of metal dinitrosyl complexes with alkenes and their application to C-H bond functionalization," Accounts of Chemical Research, vol. 47, no. 2, pp. 517-529, 2014.

[11] J. Biellman, H. Hemmer, and J. Lavisalles, The Chemistry of Alkenes, Edited by J. Zabicky, Interscience, New York, NY, USA, 1970.

[12] M. Schröder, "Osmium tetraoxide cis hydroxylation of unsaturated substrates," Chemical Reviews, vol. 80, no. 2, pp. 187-213, 1980.

[13] M. Schröder and E. C. Constable, "Direct spectroscopic evidence for the formation of an asymmetric intermediate in the oxidation of alkenes by osmium tetraoxide," Journal of the Chemical Society, Chemical Communications, no. 13, pp. 734736, 1982.

[14] C. P. Casey, "The structure of intermediates formed in the reaction of osmium tetroxide with 1,1-diphenylethylene," Journal of the Chemical Society, Chemical Communications, no. 3, pp. 126127, 1983.

[15] T. H. Upton, "Activation of single-bond cleavage processes on metal surfaces: a comparison of dissociative hydrogen adsorption with simple gas-phase exchange reactions," Journal of the American Chemical Society, vol. 106, no. 6, pp. 1561-1571, 1984.

[16] T. H. Upton and A. K. Rappé, "A theoretical basis for low barriers in transition-metal complex $2 \pi+2 \pi$ reactions: the isomerization of the dicyclopentadienyltitanium complex $\mathrm{Cp}_{2} \mathrm{TiC}_{3} \mathrm{H}_{6}$ to $\mathrm{Cp}_{2} \mathrm{TiCH}_{2}\left(\mathrm{C}_{2} \mathrm{H}_{4}\right)$," Journal of the American Chemical Society, vol. 107, pp. 1206-1218, 1985.

[17] J. R. Norton, "Organometallic elimination mechanisms: studies on osmium alkyls and hydrides," Accounts of Chemical Research, vol. 12, no. 4, pp. 139-145, 1979.

[18] Wavefunction, Spartan'10 V1.1.0, Wavefunction, 2010.

[19] Y. Zhao and D. G. Truhlar, "The M06 suite of density functionals for main group thermochemistry, thermochemical kinetics, noncovalent interactions, excited states, and transition elements: two new functionals and systematic testing of four M06-class functionals and 12 other functionals," Theoretical Chemistry Accounts, vol. 120, no. 1, pp. 215-241, 2008.

[20] R. Peverati and D. G. Truhlar, "Quest for a universal density functional: the accuracy of density functionals across a broad spectrum of databases in chemistry and physics," Philosophical 
Transactions of the Royal Society A: Mathematical, Physical and Engineering Sciences, vol. 372, no. 2011, 2014.

[21] T. H. Dunning Jr. and P. J. Hay, "Gaussian basis sets for molecular calculations," in Modern Theoretical Chemistry, H. F. Schaefer III, Ed., vol. 3, Plenum, New York, NY, USA, 1976.

[22] P. J. Hay and W. R. Wadt, "Ab initio effective core potentials for molecular calculations. Potentials for the transition metal atoms Sc to Hg," The Journal of Chemical Physics, vol. 82, no. 1, pp. $270-$ 283, 1985.

[23] P. J. Hay and W. R. Wadt, "Ab initio effective core potentials for molecular calculations. Potentials for $\mathrm{K}$ to Au including the outermost core orbitals," The Journal of Chemical Physics, vol. 82, no. 1, pp. 299-310, 1985.

[24] L. E. Roy, P. J. Hay, and R. L. Martin, "Revised basis sets for the LANL effective core potentials," Journal of Chemical Theory and Computation, vol. 4, no. 7, pp. 1029-1031, 2008.

[25] T. Sperger, I. A. Sanhueza, I. Kalvet, and F. Schoenebeck, "Computational studies of synthetically relevant homogeneous organometallic catalysis involving $\mathrm{Ni}, \mathrm{Pd}, \mathrm{Ir}$, and $\mathrm{Rh}$ : an overview of commonly employed dft methods and mechanistic insights," Chemical Reviews, vol. 115, no. 17, pp. 9532-9586, 2015.

[26] I. Ahmed, R. Tia, and E. Adei, "A quantum chemical study of the mechanisms of olefin addition to group 9 transition metal dioxo compounds," SpringerPlus, vol. 5, article 867, 2016. 

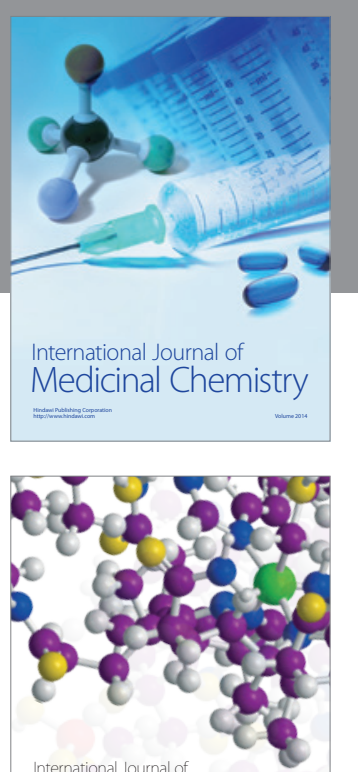

Carbohydrate Chemistry

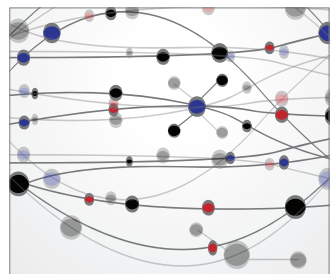

The Scientific World Journal
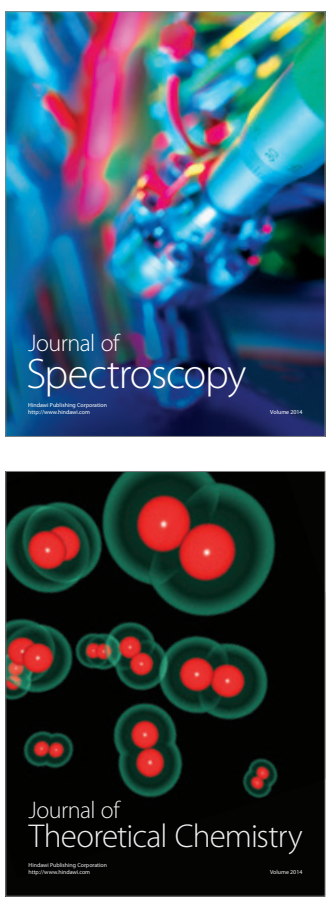
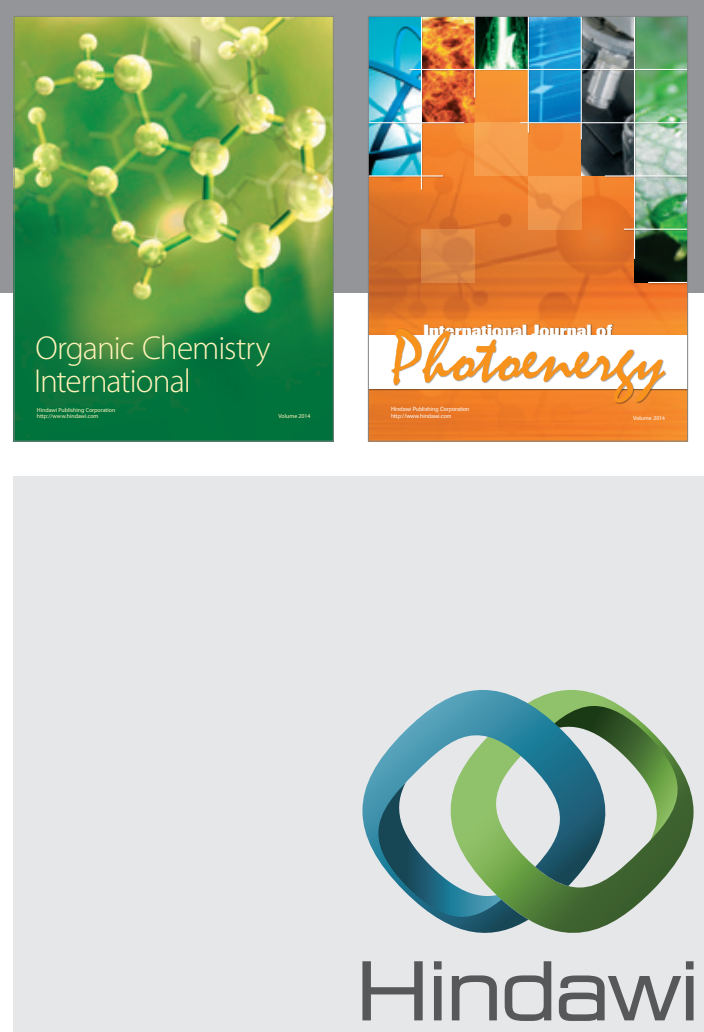

Submit your manuscripts at

http://www.hindawi.com

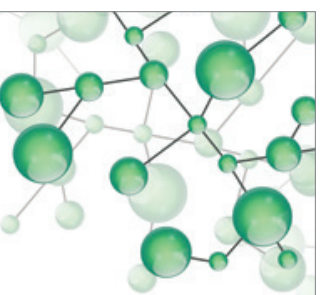

International Journal of

Inorganic Chemistry

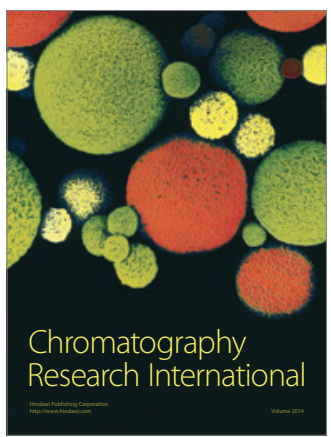

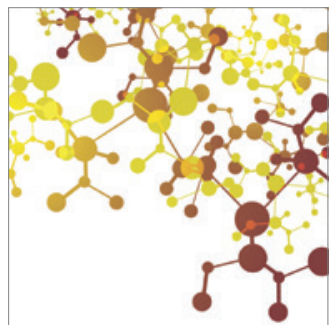

Applied Chemistry
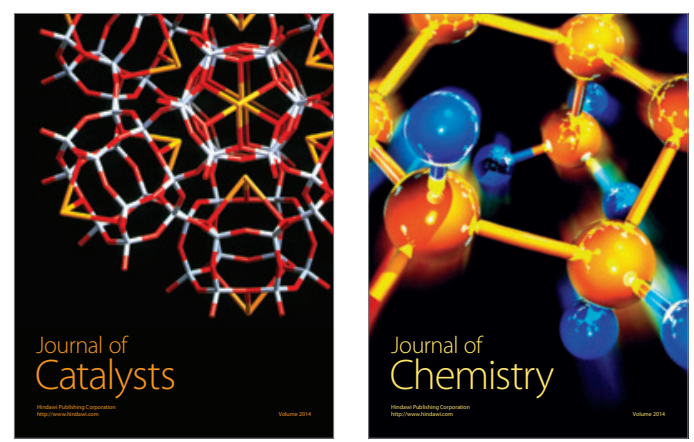
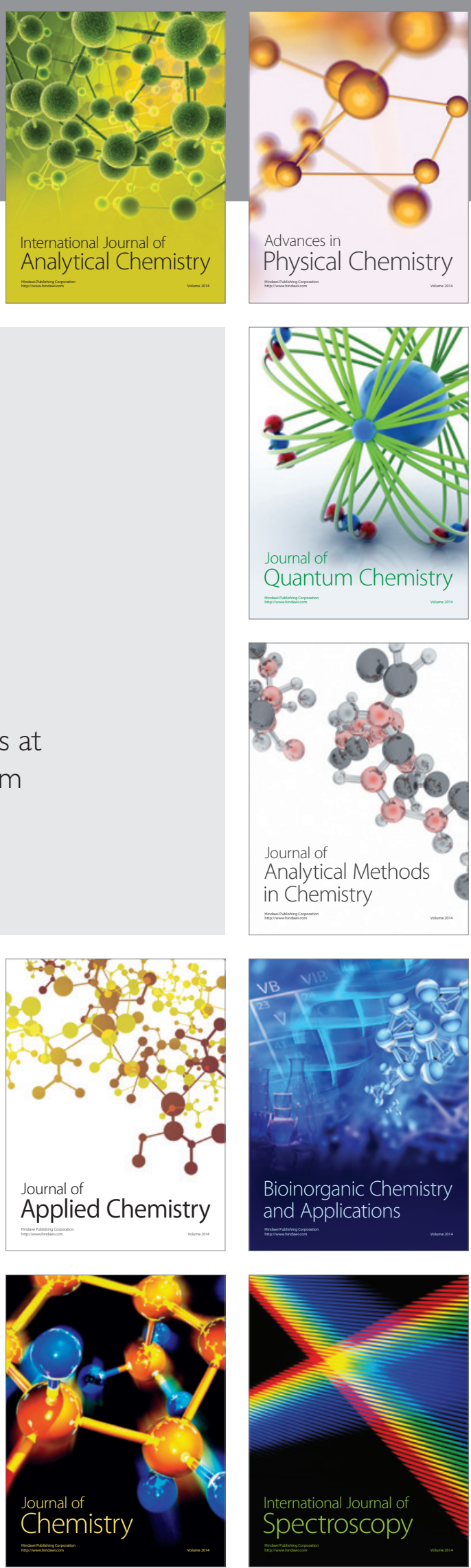